\title{
CORRELATING CELL ARCHITECTURE WITH OSTEOGENESIS: FIRST STEPS TOWARDS LIVE SINGLE CELL MONITORING
}

\author{
A.-K. Born, M. Rottmar, S. Lischer, M. Pleskova, A. Bruinink, and K. Maniura-Weber* \\ Laboratory for Materials-Biology Interactions, Empa \\ Swiss Federal Laboratories for Materials Testing and Research, CH-9014 St Gallen \\ Switzerland
}

\begin{abstract}
Cell shape and regulation of biological processes such as proliferation and differentiation are to a large degree connected. Investigation of the possible relationship between cell shape and function is therefore important for developing new material concepts for medical applications as well as developing novel cell based sensors.

Cell spreading requires a firm contact with the underlying substrate, with focal contacts (FC) being the primary sites of adhesion. They consist of a large number of clustered transmembrane proteins (integrins). FC integrins connect the cell cytoskeleton with the cell substratum. It has been demonstrated that cell spreading increases osteoblast differentiation in pre-osteoblastic progenitors. The gradual process of osteogenesis can be followed by different proteins being expressed at various time points, comprising early (e.g., bone-specific alkaline phosphatase (bALP)) and late genes (e.g., osteocalcin (OC)).

In the present study we have used immunohistochemistry and RT-PCR to determine osteogenic differentiation of human bone cells (HBC). For online monitoring, fluorescently-tagged actin and vinculin were used for transfection of HBCs. Transfection of HBCs with an OC promoter gene construct allowed us to online monitor the gradual process of osteogenesis. We found distinct changes in cell architecture upon osteogenic differentiation thus providing evidence for the connection between cell shape and functional state.
\end{abstract}

Keywords: Mesenchymal stem cells, osteogenesis, cell architecture, online monitoring, osteocalcin, collagen I.

\footnotetext{
* Address for correspondence:

K. Maniura-Weber

Laboratory for Materials-Biology Interactions, Empa

Lerchenfeldstrasse 5, CH-9014 St. Gallen, Switzerland

FAX Number: +41 712747694

Email: katharina.maniura@empa.ch
}

\section{Introduction}

Throughout life a certain quantity of cells remain in an undifferentiated stem cell-like state in which they contribute to healing processes. Mesenchymal stem cells (MSC) have been shown to facilitate fracture healing, normal bone remodelling and other tissue formation (Aubin, 2001). MSCs represent a subset of bone marrowderived stem cells and have the potential to differentiate in osteoblasts, chondrocytes, adipocytes, muscle and connective tissue cells (Aubin, 1998; Nöth et al., 2002; Pittenger et al., 1999) depending on the cues that these cells sense. For instance MSCs can be directed towards the osteogenic lineage in vitro when cultured in the presence of $ß$-glycerophosphate, ascorbic acid, vitamine $\mathrm{D}_{3}$ and a low concentration of dexamethasone (Maniatopoulos et al., 1988). As a result human MSCs (hMSCs) generated a great deal of excitement in the field of regenerative medicine as they represent a reservoir of cells for remodelling and tissue repair (Barry and Murphy, 2004). Friedenstein first showed that bone marrowderived cells have a significant proliferation capacity and are capable to form new bone when transplanted in vivo (Friedenstein, 1961).

Proliferation and differentiation of osteoprogenitors is regulated by differential expression of osteoblast associated genes including those for specific transcription factors, cell-cycle related proteins, adhesion molecules and matrix proteins (Yanaka et al., 2003). During early stages osteogenic cells initiate the synthesis of extracellular matrix (ECM), which consists primarily of collagen type I (Col I). Subsequently cells produce bALP and a variety of noncollagenous proteins, such as osteopontin (OP), osteonectin (ON), bone sialo proteinII (BSP) and OC, followed by induction of ECM calcification (Jaiswal et al., 1997; Malaval et al., 1999; Stein et al., 1990). The mRNA levels of osteoblastic marker proteins during the process of in vitro differentiation have been investigated by several groups (Byers et al., 1999; Frank et al., 2002; Shui et al., 2003; Viereck et al., 2002). Results from various studies often show high variability in gene expression levels between different individuals as well as different methods of harvesting and cultivation of cells. It has been shown by Lian and Stein (1993) that the expression of osteoblastrelated genes is developmentally responsive to steroid hormones and physiological mediators supplied in the growth media.

Cellular interaction with ECM and neighbouring cells plays a critical role in osteoblast survival, proliferation, differentiation as well as bone remodelling (Scadden, 2006; Watt and Hogan, 2000). Integrin-mediated cell 
adhesion to matrix proteins is a first step that determines the ultimate fate of the cell and therefore plays an important role in osteoblast function. For example, when osteoblasts are cultured on matrices of OP, BSP, or Col I, their proliferation is altered and differentiation is accelerated (Liu et al., 1997; Mizuno et al., 2000; Zhou et al., 1995). Surface roughness and micro- as well as nano-topography are also known to influence the activity and behaviour of osteoblasts contacting material surfaces in vivo and in vitro by modifying the integrin expression patterns (Boyan et al., 1996; Dalby et al., 2007; Sinha et al., 1994). Once integrins are bound to their ligands they form specialized protein clusters called focal adhesions (FA) (Brakebusch and Fässler, 2003). These complexes ensure substrate adhesion as well as directed assembly of actin filaments and signalling components. During the process of osteogenic differentiation an important change in the morphology of osteoblastic cells can be observed. The fibroblast-like phenotype of pre-osteoblasts changes to the flattened and polygonal shape of differentiated osteoblasts. The clear correlation between cell shape and differentiation leads to the assumption that changes in the assembly and disassembly of the actin cytoskeleton may be critical in supporting osteogenic differentiation (Rodríguez et al., 2004; Yourek et al., 2007). Cell shape is suggested to be a key regulator of MSC commitment (McBeath et al., 2004). Furthermore, it has been shown that mechanical properties of the surrounding environment influences FA structure and the cell cytoskeleton as well as cell fate (Discher et al., 2005; Engler et al., 2004; Engler et al., 2006; Kong et al., 2005; Pelham and Wang, 1997). The finding that cells are able to sense their environment has important implications for in vivo applications such as tissue regeneration and drug delivery (Rehfeldt et al., 2007).

Introduction of modified genes by transfection is a useful tool to investigate protein function in living cells and is currently performed using both viral and nonviral based methodologies. The genetic modification of primary cells using nonviral methods (like nucleofection, lipofection or electroporation) is in general less efficient (Zaragosi et al., 2007) when compared to viral techniques which however have many disadvantages, such as safety risks. Nucleofection has been successfully used for transfection of several primary cell types including human and mouse stem cells (Aluigi et al., 2006; Cesnulevicius et al., 2006; Lorenz et al., 2004). As differentiation patterns of hMSC have been shown not to be altered by nucleofection (Wiehe et al., 2007), this method is valuable to induce transient as well as stable transgene expression in bone marrow-derived stem cells.

In the present study, immunohistochemical staining for bALP, Col I and quantitative RT-PCR of osteoblastic genes (bALP, Col I and OC) were performed to demonstrate differentiation of human trabecular bone-derived osteoblast precursor cells towards osteoblasts. In addition immunohistochemical staining of actin and vinculin indicated changes in cell architecture accompanying osteogenesis. For live cell monitoring of cell adhesion and cytoskeletal proteins HBCs were nucleofected with gene constructs expressing versions of the proteins vinculin and actin that are fused to green fluorescent protein.
Furthermore, nucleofection of HBCs with a gene construct reporting for $\mathrm{OC}$ promoter activity allowed online monitoring of differentiation. The study presents first steps using online monitoring to follow osteogenic differentiation. Hence, our approach appears to be suitable for later investigations of the behaviour of cells in contact with material surfaces developed for bone repair approaches as well as biosensors.

\section{Materials and Methods}

\section{Isolation and culture of human trabecular bone- derived cells}

Bone marrow specimens were obtained during surgical hip replacement procedures of otherwise healthy patients (four male and four female patients of an age between 50 and 79 years) after informed consent. HBC cultures were prepared from pieces of trabecular bone as described previously (Auf'mkolk et al., 1985; Beresford et al., 1984). Femur-derived bone marrow samples including pieces of trabecular bone were incubated in $20 \mathrm{ml}$ isolation medium (25 mM HEPES, $128.5 \mathrm{mM} \mathrm{NaCl}, 5.4 \mathrm{mM} \mathrm{KCl}, 5.5 \mathrm{mM}$ $\mathrm{D}(+)$-glucose, $51.8 \mathrm{mM} \mathrm{D}(+)$-saccharose, $0.1 \% \mathrm{BSA})$ overnight at $4^{\circ} \mathrm{C}$ and then centrifuged at $110 \mathrm{~g}$ for $15 \mathrm{~min}$ at $4^{\circ} \mathrm{C}$. The supernatant was discarded and the pellet containing the pieces of trabecular bone was washed several times with isolation medium under microscopic observation to rinse off tissue remains and cells. Five to ten pieces with a total weight of approximately $25 \mathrm{mg}$ were placed into a T75 culture flask (Cellstar T75, Greiner BioOne $\mathrm{GmbH}$, Frickenhausen, Germany) with expansion medium ( $\alpha$-MEM (minimal essential medium) supplemented with 10\% fetal bovine serum (FBS), 1\% 5 $\mathrm{mg} / \mathrm{ml}$ penicillin, $5 \mathrm{mg} / \mathrm{ml}$ streptomycin, $10 \mathrm{mg} / \mathrm{ml}$ neomycin (PSN), $1 \mathrm{ng} / \mathrm{ml}$ basic fibroblast growth factor (FGF-2)) and cultured in a humidified incubator at $37^{\circ} \mathrm{C}$ with $5 \% \mathrm{CO}_{2} / 95 \%$ air. Bone cells started to grow out onto the culture flask after one week. After three weeks cells were passaged and cultured in osteogenic medium $(\alpha$ MEM supplemented with 10\% FBS, 1\% PSN, $10 \mathrm{nM}$ dexamethasone, $50 \mathrm{mM}$ ascorbic acid phosphate, $2 \mathrm{mM}$ $\beta$-glycerophosphate and $10 \mathrm{nM} 1,25$-dihydroxyvitamin $\mathrm{D}_{3}$ ) or kept in expansion medium, respectively. Depending on further application human trabecular bone-derived cells (HBC) were either seeded in T75 flasks $\left(2 \times 10^{5}\right.$ cells) or in 6-well plates (well bottom area $9.5 \mathrm{~cm}^{2}$, Corning Inc, Corning, NY, USA) at a density of 1 or- $2 \times 10^{4}$ cells for immunohistochemistry and RT-PCR, respectively. Medium was replaced every 2 to 3 days.

\section{Immunohistochemistry}

HBCs were plated at a density of $10^{4}$ cells per well of a 6well plate and cultured in expansion or osteogenic medium for the indicated time periods, washed twice with PBS and treated with $4 \%$ paraformaldehyde $/ 0.2 \%$ Triton-X 100 for $8 \mathrm{~min}$ for fixation. For immunohistochemical staining all antibody solutions were diluted in $1.5 \%$ skim milk/ PBS. FAs were visualized by immunohistochemical staining of the intracellular FA protein vinculin using the monoclonal mouse anti vinculin (1:300, Sigma, V9131) as primary 
antibody and goat $\alpha$-mouse IgG Alexa Fluor 488 (1:400, Molecular Probes, Eugene, OR, USA; A11029) as secondary antibody. Alexa Fluor 546 conjugated phalloidine $(0.165 \mathrm{mM}$, Invitrogen, Molecular Probes, A22283) was used for staining of F-actin.

Immunohistochemical staining against osteogenic markers bALP and Col I was performed using anti-human bone alkaline phosphatase $(1: 1000$, Developmental Hybridoma Bank, Iowa City, IA, USA; cat no B4-78) or anti-collagen I (1:1000, Sigma, St Louis, MO, USA, C 2456 ) followed by incubation with either goat $\alpha$-mouse IgG Alexa Fluor 488 (1:400, Molecular Probes, A11029) or goat $\alpha$-mouse IgG Alexa Fluor 546 (1:400, Molecular Probes, A11030). Fixed and permeabilised cells were incubated with antibody or staining solutions in PBS for 1 hour at room temperature. Finally, cell nuclei were stained using 4',6-diamidino-2-phenylindole dihydrochloride (DAPI, $10 \mu \mathrm{g} / \mathrm{ml}$, Sigma, D9542) for one hour incubation at room temperature. Cells were washed three times with PBS and finally covered with $2 \mathrm{ml}$ of PBS. The samples were analysed using a fluorescence microscope (Axio Imager.M1, Carl Zeiss, Oberkochen, Germany) and filter sets corresponding to the fluorochromes of interest.

\section{Quantitative RT-PCR}

HBCs from three donors (50, 64 and 66 years of age) were assessed for the expression of bALP, Col I and OC mRNA at different time points during culture in either expansion or osteogenic medium. Cells were seeded at a density of 2 x $10^{4}$ cells per well of a 6 well plate. To determine the expression of osteogenic genes, mRNA levels quantified for days 1, 7, 14 and 21 were related to those on day zero (after cell seeding but before change of medium type) in expansion medium. Total cellular RNA was extracted using Trizol ${ }^{\circledR}$ reagent (Invitrogen) according to the manufacturer's protocol. RNA concentration was determined using a spectrometer (Nanodrop, Thermo Scientific, Waltham, MA, USA). cDNA was synthesized from identical amounts of total RNA $(1 \mu \mathrm{g})$ using the reverse transcription system iScript ${ }^{\mathrm{TM}}$ from BioRad. Synthesis (protocol: $5 \mathrm{~min}$ at $25^{\circ} \mathrm{C}, 30 \mathrm{~min}$ at $42^{\circ} \mathrm{C}, 5 \mathrm{~min}$ at $85^{\circ} \mathrm{C}$ ) was performed using a thermal cycler from BioRad (Hemel Hampstead, UK). For the amplification of osteogenic markers bALP, Col I and OC (GeneBank Accession numbers NM_000478, NM_000088 and NM_199173, respectively) primers were placed outside the junction between two exons

(alp-2-for: 5'GGACATGCAGTACGAGCTGA3';

alp-2-rev: 5'CCAGCAAGAAGAAGCTTTG3';

col-I-3-for: 5'CAGCCGCTTCACCTACAGC3';

col-I-3-rev: 5'TTTTGTATTCAATCACTGTCTTGCC3'; OsteocS3: 5'GAAGCCCAGCGGTGCA3';

OsteocAS2: 5'CACTACCTCGCTGCCCTCC3') resulting in products of $111 \mathrm{bp}, 82 \mathrm{bp}$ and $69 \mathrm{bp}$ in length, respectively. $18 \mathrm{~S}$ ribosomal RNA (18 S rRNA) (GeneBank Accession number NR_003286) was used as a normalizing standard

(18S-s2: 5'GGACAGGATTGACAGATTGATAG3';

18S-as2: 5'AGTCTCGTTCGTTATCGGAAT3'). Oligonucleotides were purchased from Microsynth AG (Balgach, Switzerland). cDNA solutions obtained by reverse transcription were diluted 1:5 for amplification of osteogenic marker mRNA or 1:50 for amplification of $18 \mathrm{~S}$ rRNA. PCR amplification from cDNA was carried out using the $\mathrm{iQ}^{\mathrm{TM}} \mathrm{SYBR}{ }^{\circledR}$ Green System (BioRad) in a total volume of $50 \mu \mathrm{l}$ containing $5 \mu \mathrm{l}$ of diluted cDNA reaction solution. The PCR reaction mix with a total volume of 45 $\mu 1$ for each sample consisted of $25 \mu$ iQ SYBR Supermix (BioRad), $100 \mu \mathrm{M}$ sense, $100 \mu \mathrm{M}$ antisense primer (in 0.1 $\mu l$ respectively) and DNase free water. All reactions were performed in triplicate. Amplification cycles consist of 4 min initial activation at $95^{\circ} \mathrm{C}$ followed by 40 cycles of 30 $\mathrm{s}$ denaturation at $95^{\circ} \mathrm{C}, 50 \mathrm{~s}$ annealing and elongation at $57^{\circ} \mathrm{C}$ and final cooling to $4^{\circ} \mathrm{C}$. The reaction was monitored and analysed using the iCycler software of the BioRad system. Expression levels for osteogenic markers were calculated by normalising the quantified mRNA amount to the $18 \mathrm{~S}$ rRNA. Data are presented as mean values from triplicate measurements and variances are calculated according to the laws of uncertainty propagation (JCGM 100:2008).

\section{Transfection of cells}

HBCs were collected at $80-90 \%$ confluence and transfected by nucleofection using the Human Mesenchymal Stem Cell Nucleofector kit (VPE-1001, Amaxa Biosystems, Cologne, Germany) following the manufacturer's protocol. The reporter gene construct pEGFP-Vinculin was kindly provided by Peter Fromherz (MPI Martinsried, Germany). Plasmid pEGFP-Actin was generated by subcloning an $\mathrm{XhoI} / \mathrm{BamHI}$ actin fragment from pDsRed Monomer actin (Clontech, Saint-Germainen-Laye, France) into pEGFP-N1 (Clontech). A vector that contains $3.8 \mathrm{~kb}$ of the human $\mathrm{OC}$ promoter (pOCGFPtopaz) was kindly provided by David Rowe (University of Connecticut Health Center, Farmington, Connecticut, USA). To generate pOC3.8-EGFP the $3.8 \mathrm{~kb}$ HindIII/XhoI fragment was subcloned into vector pEGFP$\mathrm{C} 1$ (Clontech) by replacing the CMV promoter sequence. For the transfection, cells were pelleted and 4 to $5 \times 10^{5}$ cells resuspended in $100 \mu \mathrm{l}$ Nucleofector solution per transfection. Cell suspension was transfected with 3-4 $\mu \mathrm{g}$ of purified plasmid DNA (EndoFree Plasmid Maxi, Qiagen, Hilden, Germany) using program U-23 (for high transfection efficiency) of the nucleofector device (Nucelofector II, Amaxa Biosystems, Cologne, Germany). Transfected cells were immediately mixed with $500 \mu \mathrm{l}$ prewarmed culture medium and transferred into culture dishes containing pre-warmed medium. Cells were incubated at $37^{\circ} \mathrm{C}$ and medium was changed after $24 \mathrm{~h}$ to remove cell debris. Transfected cells cultured under expanding or osteogenic conditions were analysed either by using a fluorescence microscope (Axio Imager.M1, Carl Zeiss) or a confocal laser scanning microscope (LSM 510, Carl Zeiss) with the appropriate filter sets.

\section{Analysis of focal adhesion size}

Analysis of the FA area was performed with the image processing software ImageJ (Rasband, 1997-2009). Area measurements were made on randomly selected FAs of cells that were cultured under proliferating or differentiating conditions for 10 days after 


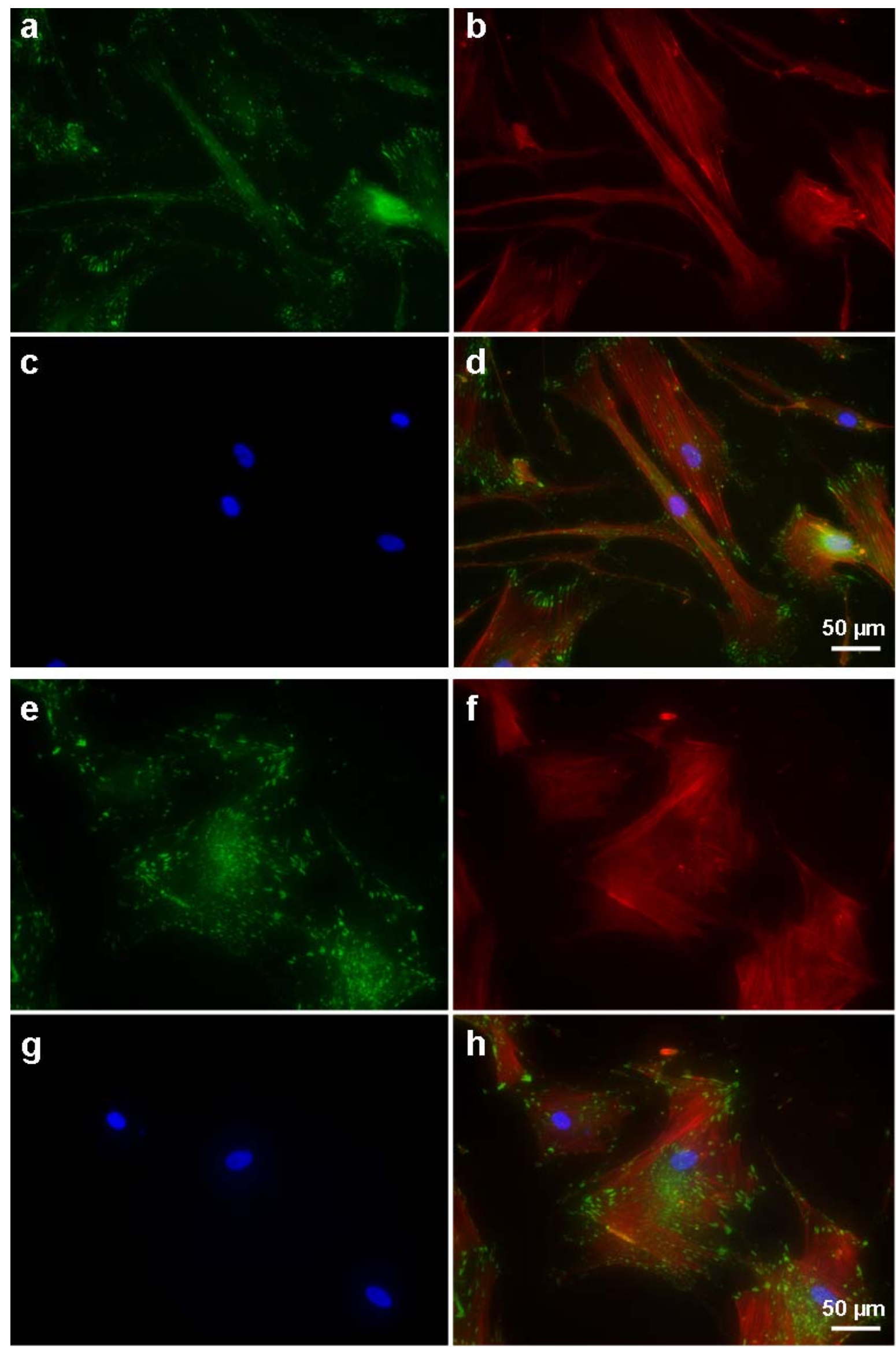

Figure 1. Immunohistochemical staining of HBCs cultivated in expansion (a-d) and osteogenic (e-h) medium against vinculin $(\mathrm{a}, \mathrm{e})$, actin $(\mathrm{b}, \mathrm{f})$ and nuclei $(\mathrm{c}, \mathrm{g})$ after 10 days of cultivation. Merge of images $(\mathrm{d}, \mathrm{h})$ presents a greater extent of FAs and concomitantly a changed distribution of actin fibres in osteogenic cells compared to expanding HBCs. 


\section{patient 1}

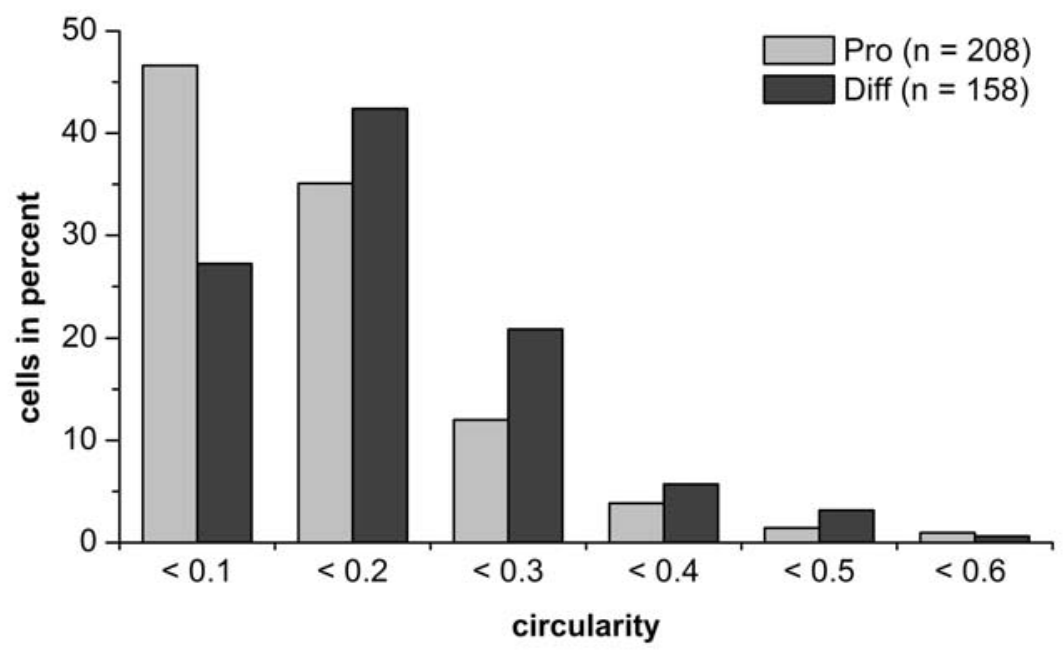

Figure 2. Determination of the individual cell circularity of HBCs cultured in expansion (light grey bars) and osteogenic medium (dark grey bars) for 10 days. Circularity values were grouped and the frequency of occurrences is illustrated as cells in percent. In total 208 proliferating and 158 differentiating cells were examined (See data from two additional patients in supplementary Fig. 2.).

immunohistochemical staining against vinculin. Regions of interest (ROI) containing single FA sites were defined using the ImageJ freehand tool. In total, the areas of 659 FAs from thirteen proliferating cells and 673 FAs from fourteen differentiating cells were determined.

\section{Cell shape analysis}

Cell shape of proliferating and differentiating HBCs was investigated using the Cell Profiler cell image analysis software (Carpenter et al., 2006). Cells from three different donors were cultured under expanding or osteogenic conditions for 10 days, fixed and immunohistochemically stained for actin and cell nuclei. Fluorescence images of isolated cells were taken with the Axio Imager.M1 fluorescence microscope. Shape features (area, perimeter) of single cells were extracted by the Measure Object Area Shape module of Cell Profiler (see supplementary Fig. 1). Cell circularity was calculated according to the following formula: circularity $=\left(4^{\prime} \mathrm{p}^{\prime}\right.$ area $) /$ perimeter $^{2}$, whereas a circularity value of 1.0 represents a perfect circular morphology and a value of 0.0 indicates an elongated polygon (Kazmers et al., 2009). For better visualisation of results, individual circularity values of proliferating and differentiating cells were sorted in circularity classes to intervals of 0.1 (ranging from zero to one). For three different patients a total number of 208, 126 and 147 of proliferating cells per patient were used for calculation of individual circularity. The total number of differentiating cells per patient used to determine cell circularity was 158 , 180 and 281, respectively.

\section{Results}

\section{Cytoskeletal structure during osteogenic differentiation}

During differentiation gradual changes of actin cytoskeleton organisation in HBCs were observed which result in different cell shapes of cells cultured in expansion and osteogenic medium. Cells grown in expansion medium appeared spindle-shaped whereas cells cultured under osteogenic conditions for 10 days showed a more flattened and polygonal morphology (Fig. 1). FAs in osteogenic cells appeared larger in contrast to those in expanding cells as judged by comparison. When calculating the area of randomly selected FAs from expanding cells using the ImageJ software we obtained a mean value of $8.01 \pm 4.08$ $\mu \mathrm{m}^{2}$. By contrast, the mean area of FAs of osteogenic cells was $11.83 \pm 6.59 \mu \mathrm{m}^{2}$. In addition, distribution of actin stress fibres is altered in differentiated cells. In undifferentiated cells stress fibres are thin and arranged in parallel to the cell orientation. By contrast, actin fibres of osteogenic cells appeared to be more prominent. The differences of cell shape were confirmed by measuring the circularity of individual cells from three different donors. Fig. 2 shows the distribution of circularity values from one representative donor. Under expanding conditions cells tend to have a more elongated shape as shown by the fact that a larger number of proliferating cells have a circularity value in the range between zero and 0.1 . By contrast the majority of cells that undergo osteogenic differentiation are characterised by higher circularity values indicating the cells tendency to spread to a spherical shaped area. Even though the distributions of circularity values from the three donors differ they individually show the above described trend (for additional data see supplementary Fig. 2).

For live monitoring of cytoskeletal structures HBCs were cultured in expansion or osteogenic medium for 10 days prior nucleofection with reporter gene constructs pActin-EGFP or pVinculin-EGFP (Fig. 3). Concerning different medium conditions, no apparent differences in transfection efficiency were seen $48 \mathrm{~h}$ post-transfection. Transfected cells cultured under proliferative conditions exhibit the characteristic fibroblast-like phenotype and long, thin fluorescent stress fibres in longitudinal 

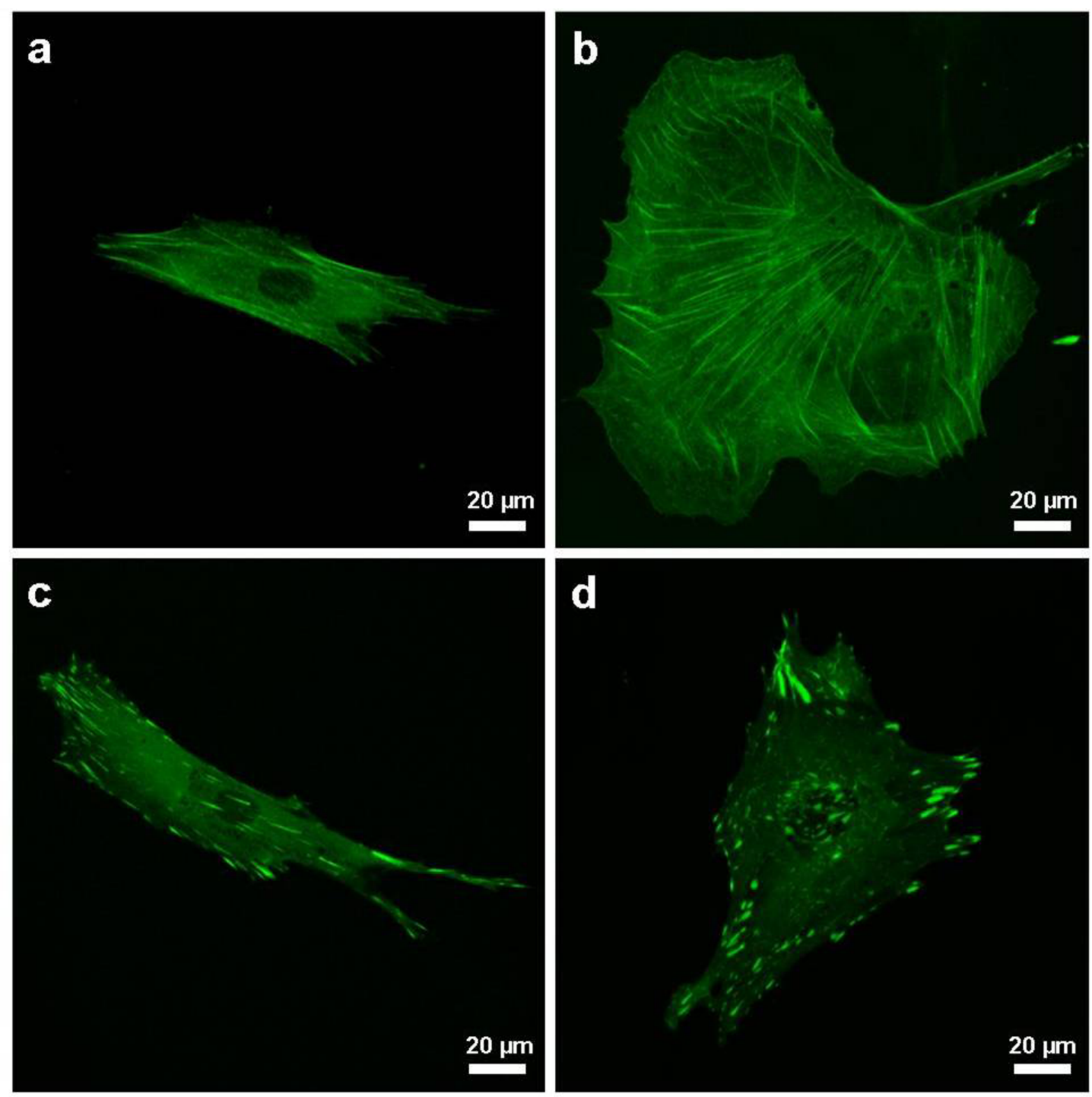

Figure 3. Representative images of cells expressing Actin-EGFP (a, b) and Vinculin-EGFP (c, d) at day 2 post transfection. Cells were cultured in expansion $(a, c)$ or osteogenic medium $(b, d)$ for 10 days prior transfection. Single cells are depicted to view distribution of fluorescently-tagged proteins in detail.

orientation. Furthermore, FAs are slightly concentrated at the narrow cell endings as indicated by accumulation of green fluorescence of vinculin-EGFP in these regions. Cells cultured in osteogenic medium spread to a larger area and showed a prominent actin cytoskeleton. Fluorescent actin fibres of differentiated cells appeared thicker than those in expanding cells and span in all directions within the irregular shaped cell. The dimensions of FAs visualized by fluorescently tagged vinculin were more prominent compared to vinculin-EGFP in proliferating cells.

\section{Immunohistochemical staining for osteogenic markers}

After 10 days of incubation in expansion or osteogenic medium HBCs were fixed and stained for bALP or Col I as well as nuclei (Fig. 4). The qualification of bALP as marker for osteoblast differentiation was proven by the clear difference of bALP staining observed in cells cultured in osteogenic medium compared to those kept in expansion medium. bALP positive cells appeared well spread and showed a uniform distribution of intense green fluorescence indicating a homogeneous dispersion of the protein over the total cell. Fluorescence intensity of cells kept in expansion medium was rather low when stained for Col I. In contrast, under osteogenic conditions latter fluorescence was significantly increased. Col I staining appeared less homogeneously distributed over the cell compared to bALP staining and was more concentrated around the cell nuclei.

HBCs were transfected with reporter gene construct pActin-EGFP or pVinculin-EGFP. After 48 hours of cultivation in either proliferation or differentiation medium HBCs were fixed and immunohistochemically stained for bALP (Fig. 5a-p). Cells previously cultured in osteogenic medium showed accumulation of bALP whereas cells cultured in expansion medium were negative for bALP staining (red, Fig. 5d, h, i, p). The majority of bALP positive cells showed a well spread phenotype (Fig. 5h, p). Furthermore, the appearance of fluorescent actin stress 

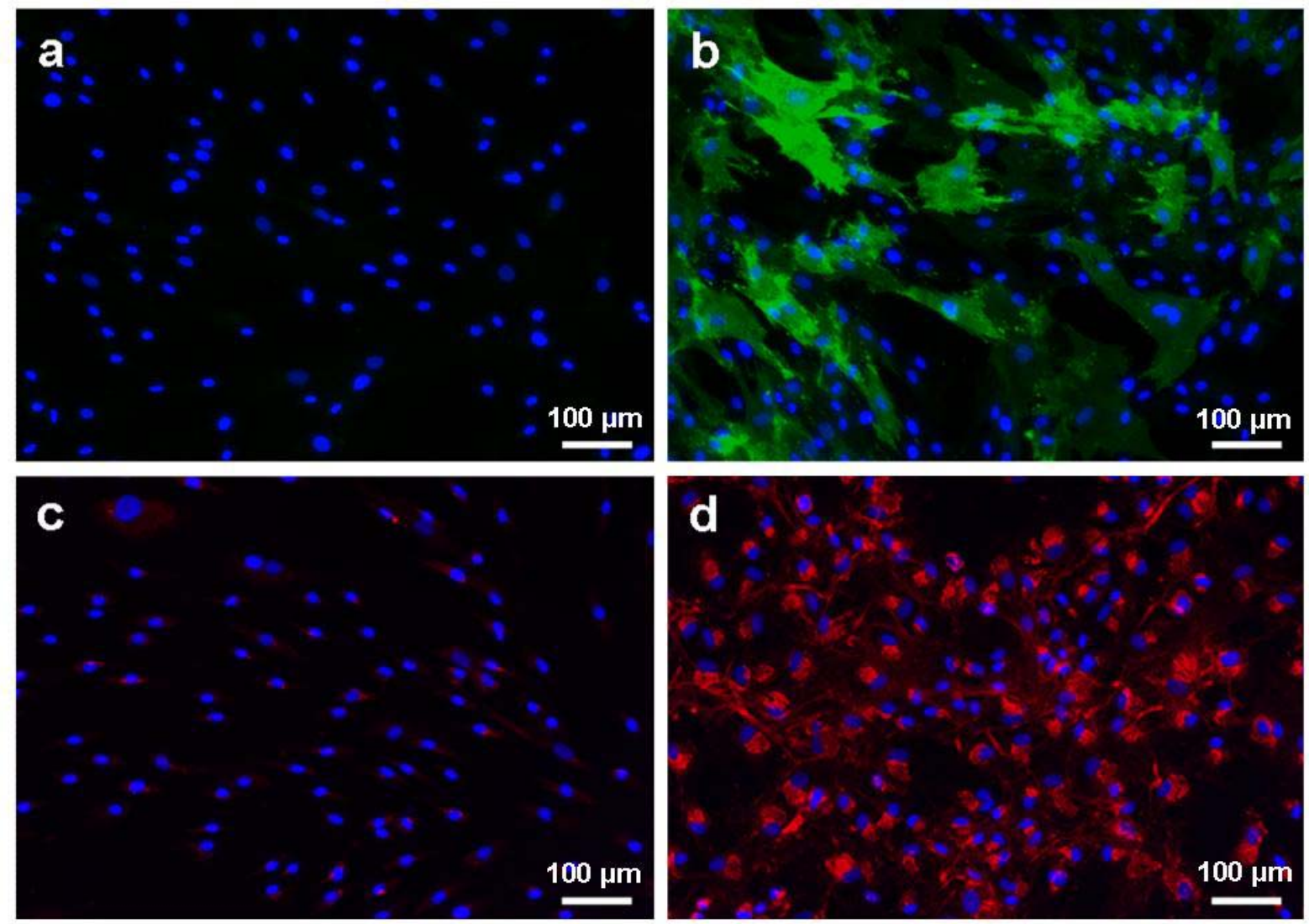

Figure 4. Comparison of HBCs cultured in expansion (a, c) or osteogenic medium (b, d). Cells were fixed and stained for bALP (green; a, b) and Col I (red; c, d); nuclei (blue) after 10 and 14 days of cultivation, respectively. Higher levels of bALP and Col I are observable in cells growing in osteogenic medium indicating osteogenic differentiation of these cells.

fibres and fluorescent vinculin seemed not to be affected by the staining procedure.

\section{Gene expression analysis}

The relative expression levels of bALP, OC and Col I were examined in cells from three different donors. Representative mRNA levels from one donor are shown in Fig. 6. Relative expression of bALP is increased more than 10 -fold on day 7 relative to day 0 when HBCs were cultured in osteogenic medium (Fig. 6a). In the following days of osteogenic cultivation relative gene expression of bALP was at least 15-fold higher than the expression levels of cells under proliferative conditions. Relative expression of bALP mRNA in proliferating cells remained on a basal level and showed no increase during the cultivation period. OC expression increased from day 0 to day 7 when cultured in osteogenic medium and showed a small increase of expression on day 21 (Fig. 6b). In contrast, OC expression in cells kept under proliferating conditions remained on the same low expression level as on day 0 compared to cells kept in osteogenic medium. Col I expression increased under osteogenic conditions up to day 7 (Fig. 6c). On days 14 and 21 cells kept under osteogenic regime showed a reduced Col I expression compared to day 7 . Relative expression levels of osteoblastic genes in proliferating cells remained low during the 21 days of culture and never reached the level of osteogenic cells. Although the relative expression levels from three donors differ from each other they all follow the same trend (see data from two additional patients in supplementary Fig. 3).

\section{Transfection with pOC3.8-EGFP}

For online monitoring of osteogenic differentiation HBCs were transfected with plasmid pOC3.8-EGFP followed by 14 days of cultivation in expansion or osteogenic medium (Fig. 7). One day after transfection no green fluorescent cells were detected either in osteogenic or expanding medium. With progressing time an increasing number of fluorescent cells appeared under osteogenic conditions, indicating that in a larger number of cells the OC promoter was active. During cultivation in expansion medium OC promoter activity was not zero but present in only a low number of cells as visualised by the fluorescence of some single cells. Even though some promoter activity is apparent in expanding cells at later time points, under osteogenic conditions much more cells displayed green fluorescence as estimated from comparison with bright field images. Transfected HBCs cultivated under proliferative conditions for 14 days showed hardly any staining for bALP. In contrast, under osteogenic conditions cells showed strong fluorescence signal of bALP staining, thus indicating occurrence of osteogenesis (Fig. 7, bottom). 


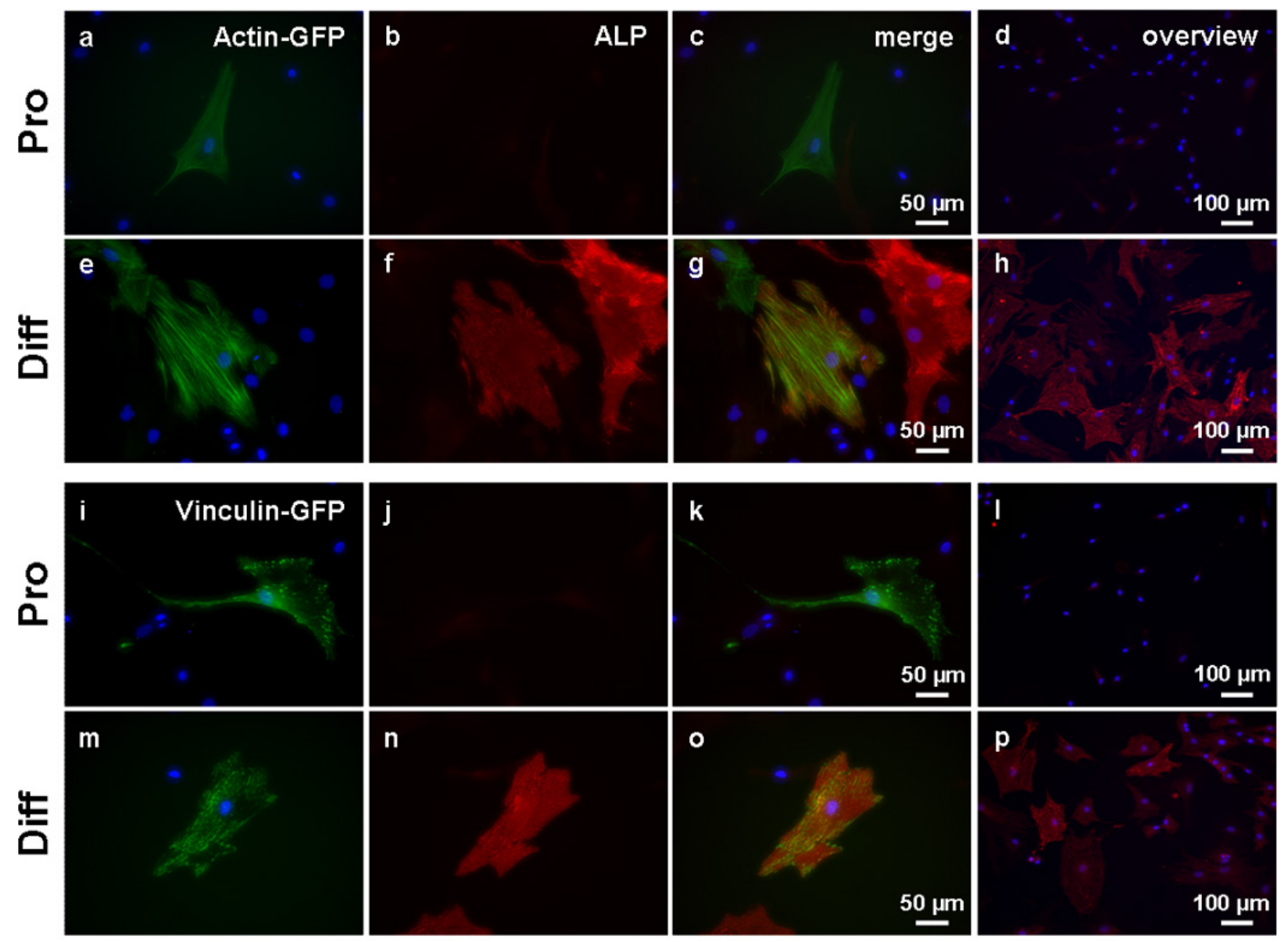

Figure 5. Immunohistochemical staining against bALP (a-p) of HBCs. Cells were transfected with Actin-EGFP (ah) or Vinculin-EGFP (i-p) and cultured in expansion or osteogenic medium. Merged images (c, g, k, o) and overview images of bALP staining $(\mathrm{d}, \mathrm{h}, \mathrm{l}, \mathrm{p})$ are shown.

\section{Discussion}

Cell differentiation is characterised by fundamental changes in expression pattern of state specific proteins as well as changes in cell morphology (Frank et al., 2002). In this study, we have simultaneously examined the expression of characteristic bone specific markers and morphological changes of human MSCs during osteogenic differentiation in order to correlate both characteristics. By performing RT-PCR assays we demonstrated that expression of three bone specific genes is up-regulated during 21 days of culture under osteogenic conditions. We further demonstrated that gene expression levels of bALP, OC and Col I do not or only slightly increase during culture in expansion medium. The results of our RT-PCR assays have shown that $\mathrm{OC}$ is already highly expressed at day seven and expressed at a still higher level on day 21 under osteogenic cultivation conditions. Therefore OC appears to be a reasonably early marker of osteogenic differentiation at the level of gene expression in the chosen cell system. We have used immunofluorescence of bALP and Col I to effectively distinguish between proliferating and differentiating HBCs. Methods like RT-PCR or immunohistochemistry represent endpoint determinations and result in only limited information about the status of a single cells condition. To allow online monitoring of single cells over a defined period of time we used reporter gene constructs for transfection of HBCs. For online monitoring of osteogenic differentiation by a gene construct reporting for activity of the human OC promoter HBCs were transfected with an appropriate DNA construct. Using the OC promoter construct we were able to monitor osteogenic differentiation of a cell population over a period of 14 days. A similar gene construct has previously been used to generate transgenic mice where green fluorescence in long bone and calvaria was seen which was simultaneously associated with strong OC expression (Bilic-Curcic et al., 2005). Under osteogenic conditions we noted an increasing number of fluorescent cells which indicates activity of the OC promoter. By immunohistochemical staining of bALP we could show that within the period of 14 days transfected cells underwent osteogenesis when cultured in osteogenic medium. In line with these results we could additionally show that at this time point there is also a strong increase in OC mRNA synthesis indicating a direct correlation between these two endpoint markers. At later time points of cultivation in expansion medium a low number of single fluorescent cells also emerge. This leads to the assumption 
$x$

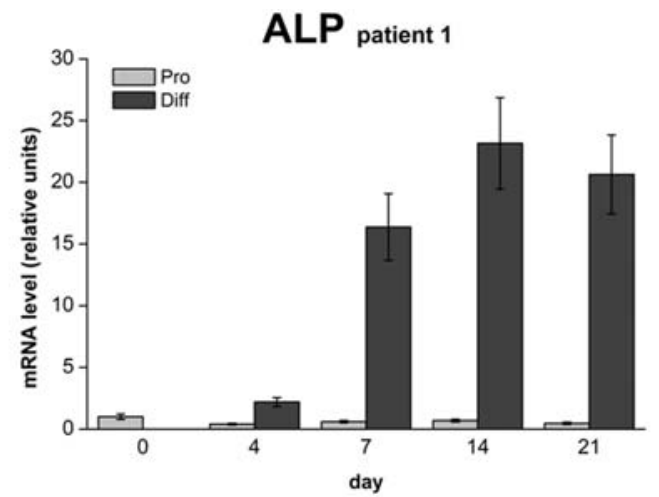

b

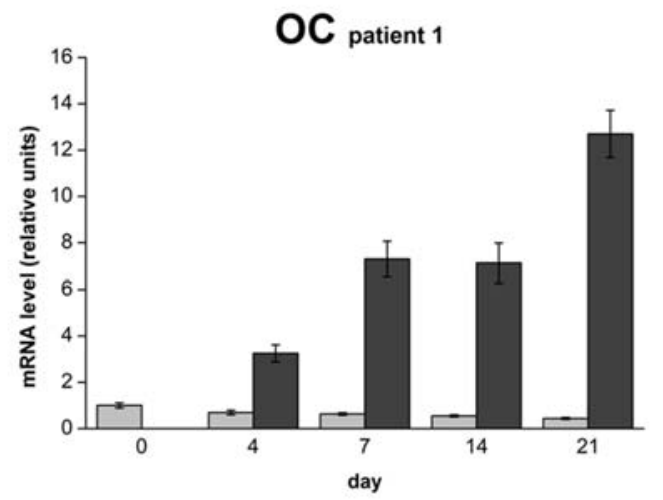

C

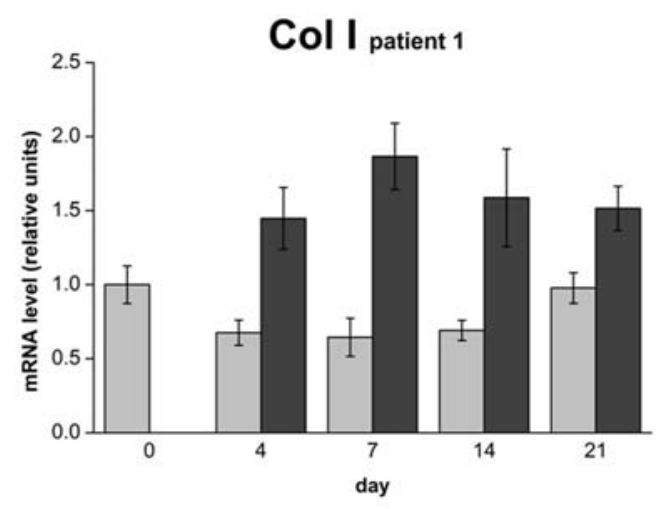

Figure 6. Representative data of the mRNA levels of bALP, OC and Col I of human osteoprogenitor cells grown under proliferation and osteogenic medium conditions. Data from one patient are shown (see data from two additional patients in supplementary Fig. 3). Quantitative RT-PCR analysis confirms the specificity of the cultivation conditions as all three genes are expressed at higher level in differentiating cells.
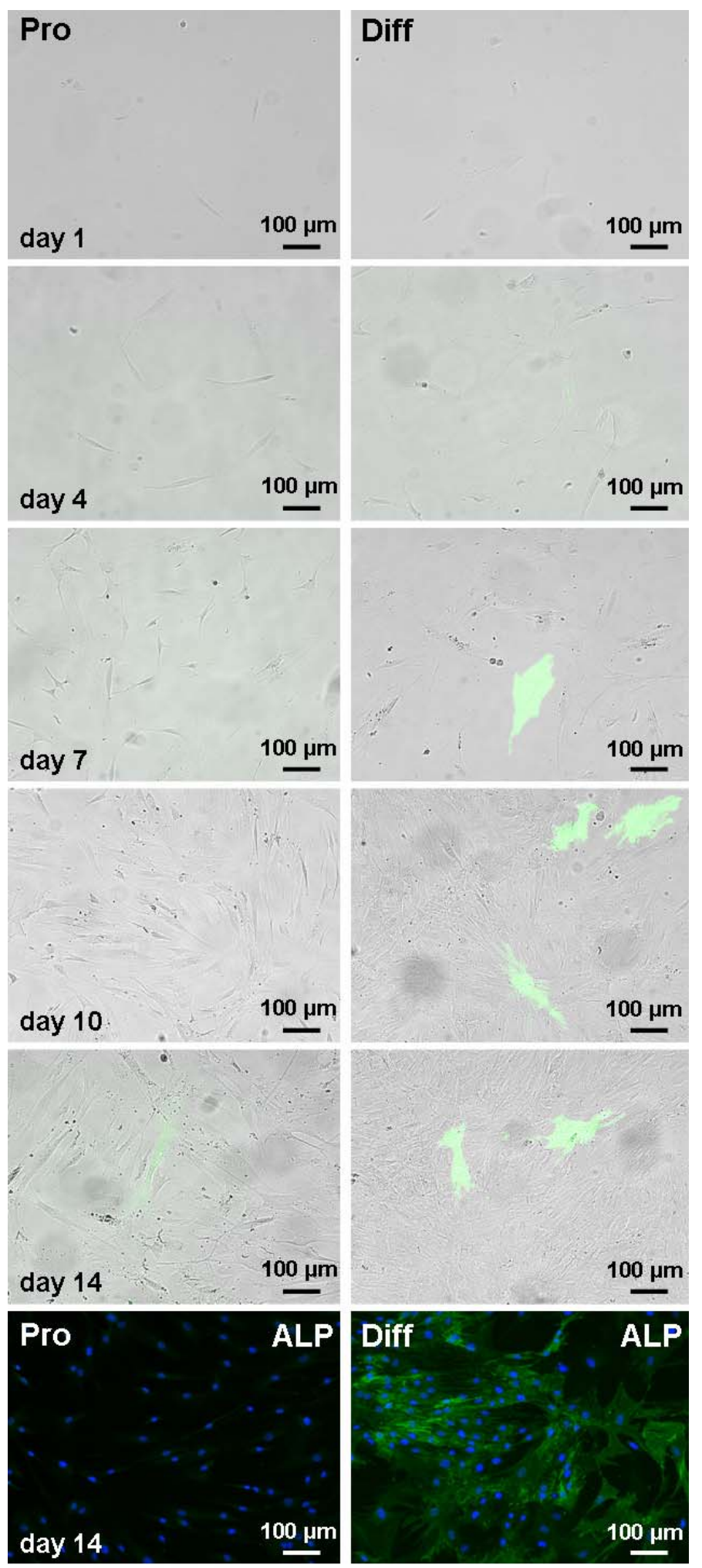

Figure 7. Expression of green fluorescent protein under the control of the human OC promoter at days 1, 4, 7, 10 and 14 visualized by fluorescence microscopy. Post-transfection, HBCs were cultured in expansion or osteogenic medium. Expression of GFP is increased in osteogenic cells at days 7, 10 and 14 compared to proliferating cells. Merged images of bright field and fluorescent images are shown to allow judgement of total cell density. On day 14 transfected cells were fixed and stained for bALP. 
that these cultures represent a heterogeneous population of cells with a small number of them being able to differentiate even without osteo-inductive medium additives. It can also not be excluded that the proliferation medium contains some osteogenic stimuli as constituent of the added FCS. Transfection with a control vector for CMV promoter driven expression of GFP resulted in approximately $25 \%$ of green fluorescent cells 2 days posttransfection. For the same amount of OC promoter construct and consistent parameters for nucleofection the transfection efficiency was expected to be in the same range but cannot be guaranteed using the chosen reporter. Nevertheless, the use of the reporter gene construct enables us to differentiate effectively between proliferating and differentiating cells.

Upon differentiation major changes in the actin cytoskeleton lead to alterations in cell morphology. By determination of the circularity of single cells we were able to show that proliferating cells tend to display a more elongated cell shape whereas osteogenic cells tend to spread in a more spherical shape. Our results, obtained by immunohistochemistry and transfection show, that under expanding conditions, thin actin stress fibres are running in parallel to the longitudinal cell axis. In contrast, during osteogenic differentiation the actin cytoskeleton is reorganised which results in thick non-aligned actin stress fibres (figures 3 and 5). Similar changes in the organisation of actin stress fibres have been previously described by Rodríguez et al. (2004) and Yourek et al. (2007). Cell adhesion to the underlying substrate is well known to be critical for single cell viability, proliferation or differentiation. Fluorescently tagged vinculin has previously been used to demonstrate that surface characteristics of biomaterials made of either titanium or stainless steel are critical for number, size and dynamics of FAs (Diener et al., 2005). In our work, we visualised the FA protein vinculin either by immunofluorescence or by transfection of cells with EGFP-tagged vinculin. Under expanding conditions cells showed smaller FA areas compared to FA areas of differentiating cells, possibly indicating an increased cell adhesion of osteogenic cells. As integrin-mediated adhesion to components of the ECM plays a critical role in osteoblast function, cell adhesion is often used to consider biomaterial surfaces.

Our results indicate that transfection can be effectively used for gene delivery in HBCs and to monitor timedependent changes in gene activity of functional state dependent proteins or in cytoskeletal changes in case of gene constructs of cytoskeletal proteins fused to a fluorescent protein. Osteoblast adhesion to biomaterials produced for medical implants is known to be highly affected by surface characteristics (e.g. topography, chemistry or surface energy) of the material (Anselme, 2000). Furthermore, the impact of substrate elasticity on differentiation of MSCs towards a particular lineage has been reported recently (Engler et al., 2006). The combination of osteogenic promoter constructs with gene constructs of cytoskeletal proteins represents a novel and powerful tool to study newly developed as well as already existing biomaterials. Using our approach the potential of a substrate to facilitate osteogenic differentiation can be defined and optimised. A possible induction of the osteocalcin promoter by hormones and growth factors present in the cultivation media can also be studied in living cells. Furthermore, our approach represents an online osteogenesis monitoring tool for studies dealing with tissue engineering approaches.

\section{Acknowledgements}

This work was supported by the European Commission through the specific targeted research project CellForce (Contract $\mathrm{N}^{\circ}$ : NMP4-CT-2005-016626) and CCMX MatLife (Switzerland).

\section{References}

Aluigi M, Fogli M, Curti A, Isidori A, Gruppioni E, Chiodoni C, Colombo MP, Versura P, D’Errico-Grigioni A, Ferri E, Baccarani M, Lemoli RM (2006) Nucleofection is an efficient nonviral transfection technique for human bone marrow-derived mesenchymal stem cells. Stem cells 24: 454-461.

Anselme K (2000) Osteoblast adhesion on biomaterials. Biomaterials 21: 667-81.

Aubin JE (1998) Bone stem cells. J Cell Biochem Suppl 30/31: 73-82.

Aubin JE (2001) Regulation of osteoblast formation and function. Rev Endocr Metab Disord 2: 81-94.

Auf'mkolk B, Hauschka P, Schwartz E (1985) Characterization of human bone cells in culture. Calcif Tissue Int 37: 228-235.

Barry FP, Murphy JM (2004) Mesenchymal stem cells: clinical applications and biological characterization. Int $\mathrm{J}$ Biochem Cell Biol 36: 568-584.

Beresford J, Gallagher J, Poser J, Russell R (1984) Production of osteocalcin by human bone cells in vitro. Effects of 1,25(OH)2D3, 24,25(OH)2D3, parathyroid hormone, and glucocorticoids. Metab Bone Dis Relat Res 5: 229-34.

Bilic-Curcic I, Kronenberg MX, Jiang J, Bellizzi M, Mina I, Marijanovic EM, Gardiner, Rowe DW (2005) Visualizing levels of osteoblast differentiation by a twocolor promoter-GFP strategy: Type I collagen-GFPcyan and osteocalcin-GFPtpz. Genesis 43: 87-98.

Boyan BD, Hummert TW, Dean DD, Schwartz Z (1996) Role of material surfaces in regulating bone and cartilage cell response. Biomaterials 17: 137-146.

Brakebusch C, Fässler R (2003) The integrin-actin connection, an eternal love affair. EMBO J 22: 2324-2333.

Byers RJ, Brown J, Brandwood C, Wood P, Staley W, Hainey L, Freemont AJ, Hoyland JA (1999) Osteoblastic differentiation and mRNA analysis of STRO-1-postitive human bone marrow stromal cells using primary in vitro culture and poly (A) PCR. J Pathol 187: 374-381.

Carpenter A, Jones T, Lamprecht M, Clarke C, Kang I, Friman O, Guertin D, Chang J, Lindquist R, Moffat J, Golland P, Sabatini D (2006) CellProfiler: image analysis software for identifying and quantifying cell phenotypes. Genome Biol 7: R100.

Cesnulevicius K, Timmer M, Wesemann M, Thomas T, Barkhausen T, Grothe C (2006) Nucleofection is the 
most efficient nonviral transfection method for neuronal stem cells derived from ventral mesencephali with no changes in cell composition or dopaminergic fate. Stem Cells 24: 2776-2791.

Dalby MJ, Gadegaard N, Tare R, Andar A, Riehle MO, Herzyk P, Wilkinson CDW, Oreffo ROC (2007) The control of human mesenchymal cell differentiation using nanoscale symmetry and disorder. Nat Mater 6: 997-1003.

Diener A, Nebe B, Luthen F, Becker P, Beck U, Neumann HG, Rychly J (2005) Control of focal adhesion dynamics by material surface characteristics. Biomaterials 26: 383-392.

Discher DE, Janmey P, Wang Y-l (2005) Tissue cells feel and respond to the stiffness of their substrate. Science 310: 1139-1143.

Engler AJ, Griffin MA, Sen S, Bönnemann CG, Sweeney HL, Discher DE (2004) Myotubes differentiate optimally on substrates with tissue-like stiffness: pathological implications for soft or stiff microenvironments. J Cell Biol 166: 877-887.

Engler AJ, Sen S, Sweeney HL, Discher DE (2006) Matrix elasticity directs stem cell lineage specification. Cell 126: 677-689.

Frank O, Heim M, Jakob M, Barbero A, Schäfer D, Bendik I, Dick W, Heberer M, Martin I (2002) Real-time quantitative RT-PCR analysis of human bone marrow stromal cells during osteogenic differentiation in vitro. $\mathrm{J}$ Cell Biochem 85: 737-746.

Friedenstein A (1961) Osteogenetic activity of transplanted transitional epithelium. Acta Anat 45: 31-59.

Jaiswal N, Haynesworth SE, Caplan AI, Bruder SP (1997) Osteogenic differentiation of purified, cultureexpanded human mesenchymal stem cells in vitro. J Cell Biochem 64: 295-312.

Joint Committee for Guides in Metrology (2008) JCGM 100:2008: Evaluation of measurement data - Guide to the expression of uncertainty in measurement (GUM). Bur. Intl. Poids et Mesures (Sèvres, France).

Kazmers NH, Ma SA, Yoshida T, Stern PH (2009) Rho GTPase signaling and PTH 3-34, but not PTH 1-34, maintain the actin cytoskeleton and antagonize bisphosphonate effects in mouse osteoblastic MC3T3-E1 cells. Bone 45: 52-60.

Kong HJ, Polte TR, Alsberg E, Mooney DJ (2005) FRET measurements of cell-traction forces and nano-scale clustering of adhesion ligands varied by substrate stiffness. Proc Natl Acad Sci U S A 102: 4300-4305.

Lian J, Stein G (1993) The developmental stages of osteoblast growth and differentiation exhibit selective responses of genes to growth factors (TGF beta 1) and hormones (vitamine D and Glucocorticoids). J Oral Implantol 19: 95-105.

Liu YK, Uemura T, Nemoto A, Yabe T, Fujii N, Ushida T, Tateishi T (1997) Osteopontin involvement in integrinmediated cell signaling and regulation of expression of alkaline phosphatase during early differentiation of UMR cells. FEBS Lett 420: 112-116.

Lorenz P, Harnack U, Morgenstern R (2004) Efficient gene transfer into murine embryonic stem cells by nucleofection. Biotechnol Lett 26: 1589-1592.
Malaval L, Liu F, Roche P, Aubin JE (1999) Kinetics of osteoprogenitor proliferation and osteoblast differentiation in vitro. J Cell Biochem 74: 616-627.

Maniatopoulos C, Sodek J, Melcher AH (1988) Bone formation in vitro by stromal cells obtained from bone marrow of young adult rats. Cell Tissue Res 254: 31793330 .

McBeath R, Pirone DM, Nelson CM, Bhadriraju K, Chen CS (2004) Cell shape, cytoskeletal tension, and rhoA regulate stem cell lineage commitment. Dev Cell 6: 483495.

Mizuno M, Fujisawa R, Kuboki Y (2000) The effect of carboxyl-terminal propeptide of type I collagen (cpropeptide) on collagen synthesis of preosteoblasts and osteoblasts. Calcif Tissue Int 67: 391-399.

Nöth U, Osyczka AM, Tuli R, Hickok NJ, Danielson KG, Tuan RS (2002) Multilineage mesenchymal differentiation potential of human trabecular bone-derived cells. J Orthop Res 20: 1060-1069.

Pelham RJ, Jr., Wang Y-l (1997) Cell locomotion and focal adhesions are regulated by substrate flexibility. Proc Natl Acad Sci U S A 94: 13661-13665.

Pittenger MF, Mackay AM, Beck SC, Jaiswal RK, Douglas R, Mosca JD, Moorman MA, Simonetti DW, Craig S, Marshak DR (1999) Multilineage potential of adult human mesenchymal stem cells. Science 284: 143147.

Rasband WS (1997-2009). ImageJ, U. S. National Institute of Health, Bethesda, Maryand, USA

Rehfeldt F, Engler AJ, Eckhardt A, Ahmed F, Discher DE (2007) Cell responses to the mechanochemical microenvironment - Implications for regenerative medicine and drug delivery. Adv Drug Deliv Rev 59: 13291339.

Rodríguez JP, González M, Ríos S, Cambiazo V (2004) Cytoskeletal organization of human mesenchymal stem cells (MSC) changes during their osteogenic differentiation. J Cell Biochem 93: 721-731.

Scadden DT (2006) The stem-cell niche as an entity of action. Nature 441: 1075-1079.

Shui C, Spelsberg TC, Riggs BL, Khosla S (2003) Changes in Runx $2 /$ Cbfa1 expression and activity during osteoblastic differentiation of human bone marrow stromal cells. J Bone Miner Res 18: 213-221.

Sinha R, Morris F, Shah S, Tuan R (1994) Surface composition of orthopaedic implant metals regulates cell attachment, spreading, and cytoskeletal organization of primary human osteoblasts in vitro. Clin Orthop Relat Res 305: 258-72.

Stein GS, Lian JB, Owen TA (1990) Relationship of cell growth to the regulation of tissue-specific gene expression during osteoblast differentiation. FASEB J 4: 3111-3123.

Viereck V, Siggelkow H, Tauber S, Raddatz D, Schutze N, Hüfner M (2002) Differential regulation of Cbfa1/ Runx2 and osteocalcin gene expression by vitamin-D3, dexamethasone, and local growth factors in primary human osteoblasts. J Cell Biochem 86: 348-356.

Watt FM, Hogan BL (2000) Out of Eden: stem cells and their niches. Science 287: 1427-1430. 
Wiehe JM, Ponsaerts P, Rojewski MT, Homann JM, Greiner J, Kronawitter D, Schrezenmeier H, Hombach V, Wiesneth M, Zimmermann O, Torzewski J (2007) mRNAmediated gene delivery into human progenitor cells promotes highly efficient protein expression. J Cell Mol Med 11: 521-530.

Yanaka N, Imai Y, Kawai E, Akatsuka H, Wakimoto K, Nogusa Y, Kato N, Chiba H, Kotani E, Omori K, Sakurai $\mathrm{N}$ (2003) Novel membrane protein containing glycerophosphodiester phosphodiesterase motif is transiently expressed during osteoblast differentiation. J Biol Chem 278: 43595-43602.

Yourek G, Hussain MA, Mao JJ (2007) Cytoskeletal changes of mesenchymal stem cells during differentiation. ASAIO J 53: 219-28.

Zaragosi L-E, Billon N, Ailhaud G, Dani C (2007) Nucleofection is a valuable transfection method for transient and stable transgene expression in adipose tissuederived stem cells. Stem Cells 25: 790-797.

Zhou HY, Takita H, Fujisawa R, Mizuno M, Kuboki Y (1995) Stimulation by bone sialoprotein of calcification in osteoblast-like MC3T3-E1 cells. Calcif Tissue Int 56: 403-407.

\section{Discussion with reviewers}

M Dalby: The results and the methodology is quite observational and it would be really exciting for the authors to intervene and try to e.g. disrupt spreading with osteogenic media through e.g. mild cytoskeletal inhibition. Or using transfection, through silencing various intergrins etc.

Authors: We agree that the methods mentioned by the reviewer would help to understand the mechanisms involved in the complex relation between osteogenic differentiation and changes in the cytoskeleton in more detail. Such studies will be included in more detailed studies of OC reporter kinetics and correlation with gene expression as well as cytoskeletal dynamics.

M Dalby: Also, they state OC as an early stage marker. I would rather argue against this - ALP is considered earlier and Runx 2 earlier still. I think Runx 2 should be a target for the authors as it is probably being regulated concomitantly with the changes in morphology and cytoskeletal remodelling rather than much further down stream.

Authors: In line with the reviewer we think that ALP and Runx2 are interesting candidates for online monitoring concepts to study osteogenesis. We also generated ALP promoter constructs with different promoter lengths in our lab. None of these constructs worked as reliable as the OC promoter construct presented in the manuscript. The specificity of the ALP promoter constructs remained very low and we decided to stop working on those promoters. With respect to Runx2, we are still working on a promoter construct- which should indicate truly early events occurring during osteogenesis.

We also fully agree with the reviewer that $\mathrm{OC}$ is generally not viewed as an early marker of osteogenesisin contrast to ALP and Runx 2 . In consideration of the fact that we observe a remarkable increase in relative mRNA expression of OC at day seven, comparable with the increase of ALP mRNA expression at the same time point, we conclude that on the level of gene expression OC can function as an early marker of differentiation. The level of transcriptional regulation is what is relevant for the promoter-based reporter strategies in the present study.

M Dalby: The authors comment of number of adhesions being important - do they think size, rather than number, could be critical to osteogenesis.

Authors: At the moment we are not able to predict what is more important - size or number of focal adhesions. Nevertheless, from our result it seems to be more relevant to compare the size of focal adhesions rather than estimating the number of focal adhesions per cell as that rate is to a large degree correlated to the spreading area of the cell. The mechanistical relevance of single focal adhesion size for the process of osteogenesis is an interesting question. The understanding of this relevance could be of value for the study of many material concepts. However, the functional (mechanical) properties of small or large focal adhesions as well as e.g. their protein content are still unknown and the interrelation of these parameters still needs to be elucidated. 


\section{Supplementary Figures}

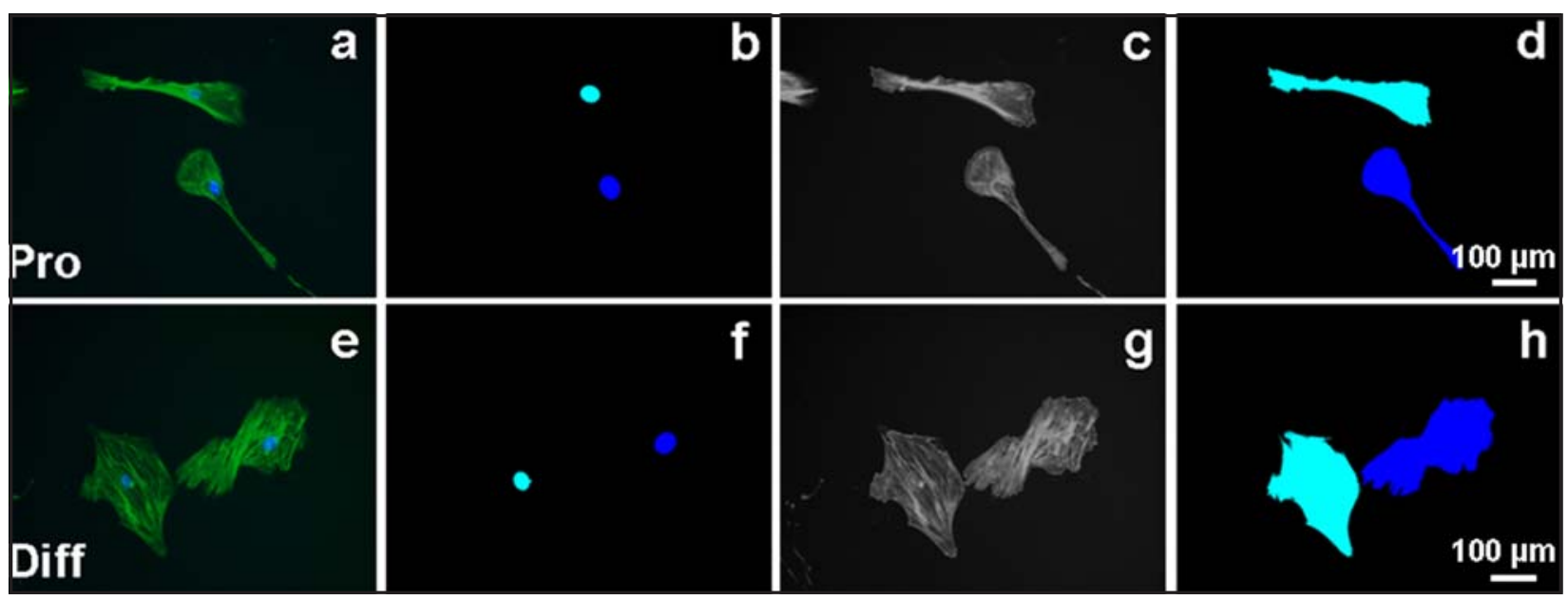

Figure S1. Representative fluorescent images of HBCs used to estimate cell perimeter and cell area are shown (a, e). Cells grown under expanding (a-d) and differentiating conditions were investigated using Cell Profiler software. First cell nuclei are identified $(b, f)$ followed by identification of nuclei-corresponding cell outlines $(c, g)$. In the last step cell area of individual cells is estimated $(d, h)$.

a

b

Figure S2. Calculated individual cell circularity values from two additional patients (a, b). Circularity values were grouped and the frequency of occurrences is illustrated as cells in percent.

\section{patient 2}

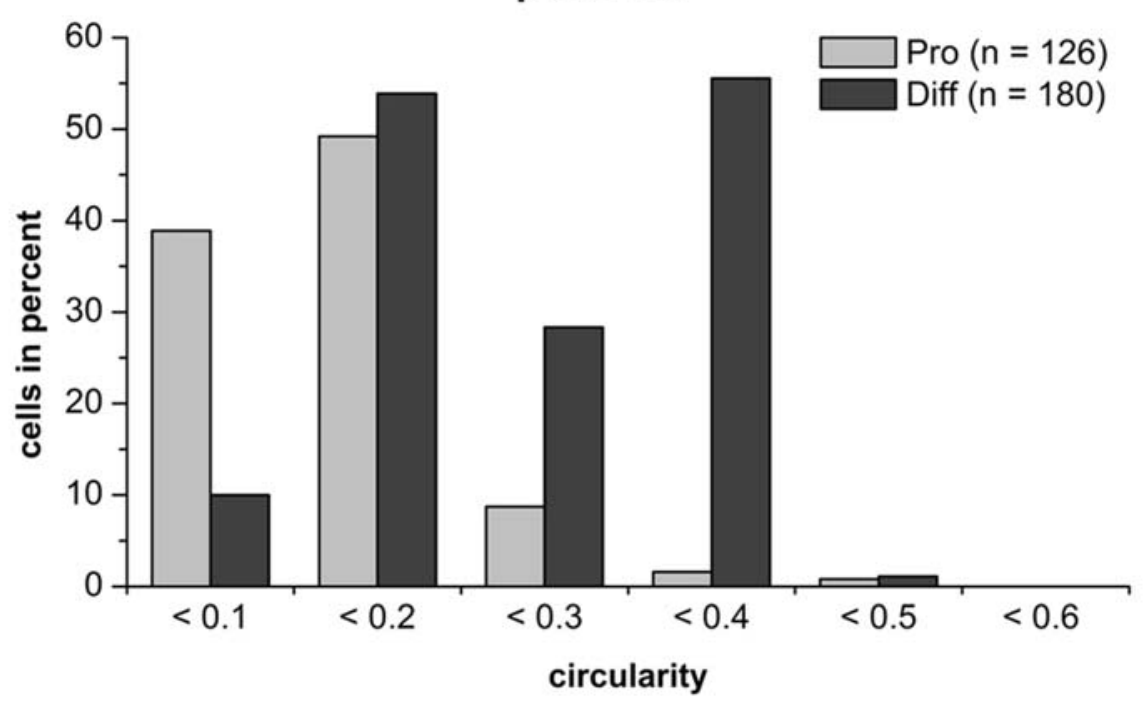

patient 3

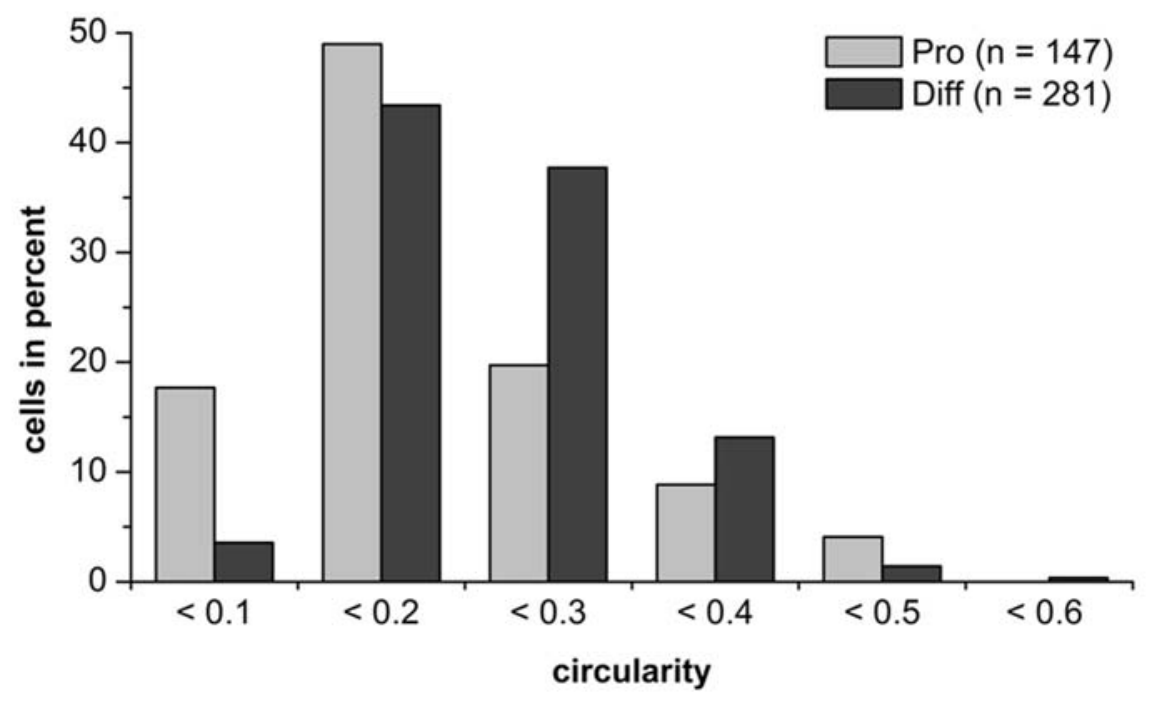


a

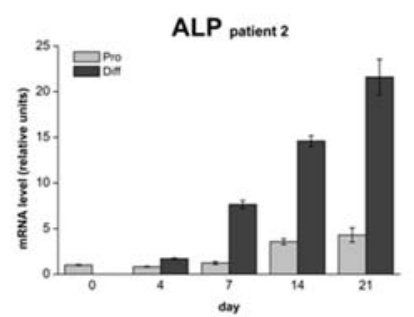

b

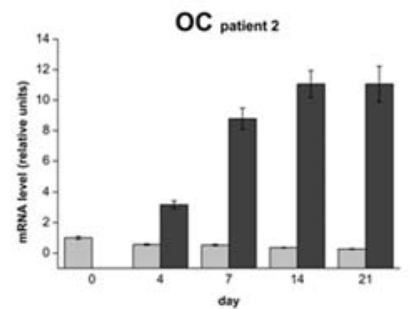

C

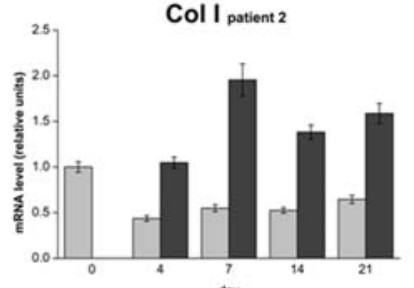

d

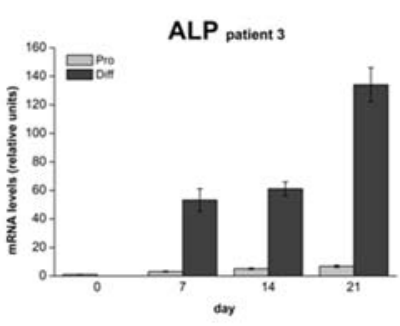

e

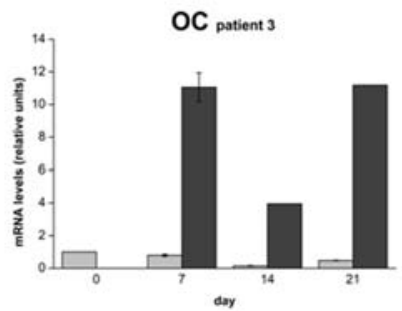

f

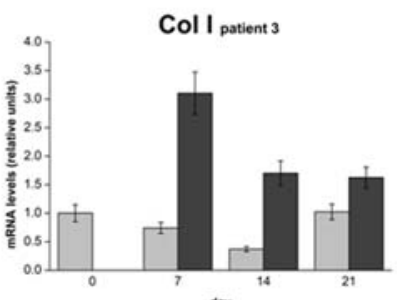

Figure S3. Data of the relative levels of bALP, OC and Col I mRNA of human osteoprogenitor cells grown under proliferation and osteogenic medium conditions from two additional patients (a-f). With ongoing cultivation under osteo-inductive conditions all three osteo-specific genes are expressed at a higher level when compared to the expression levels of proliferating cells.

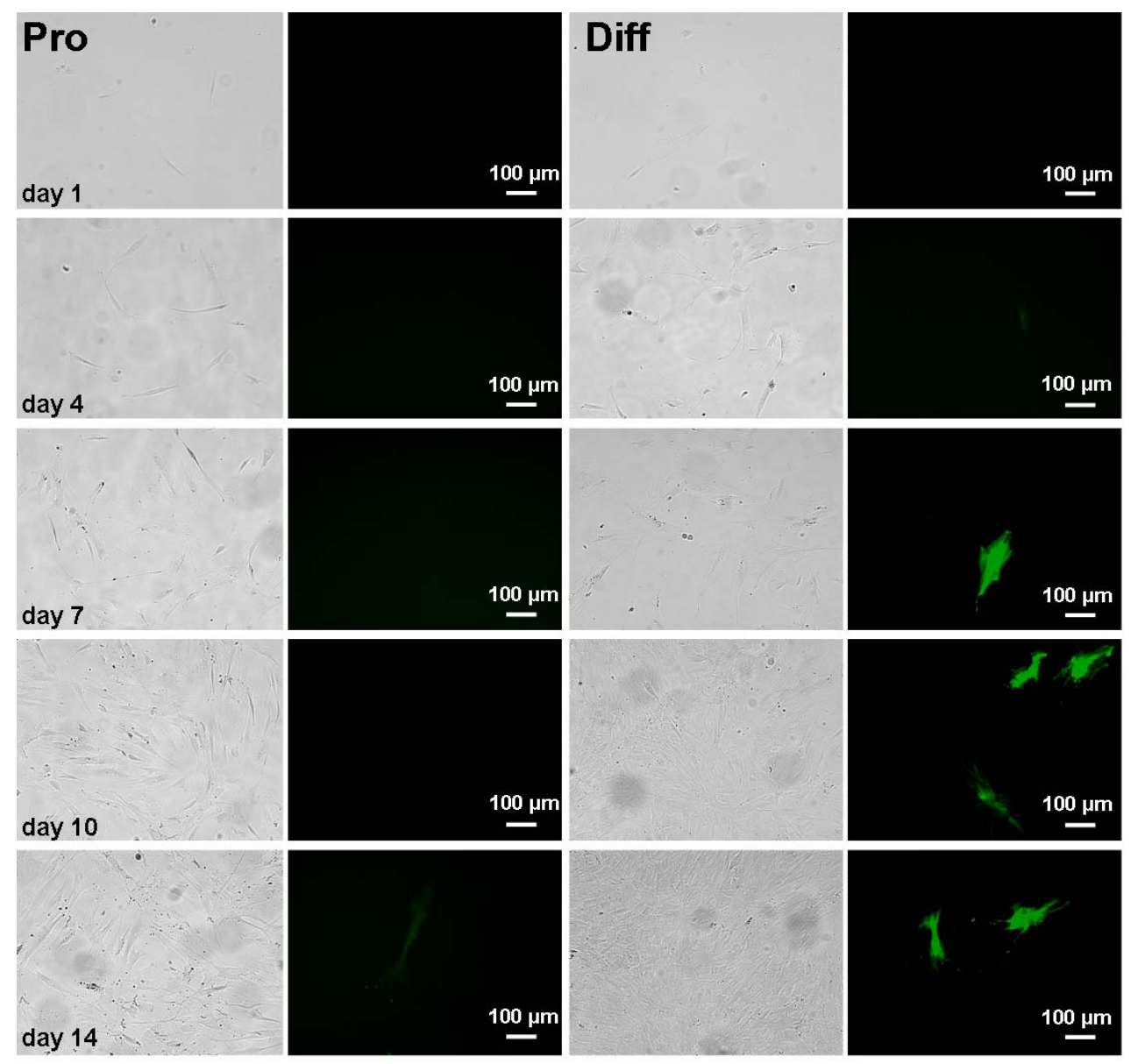

Figure S4. Transfection of HBCs with pOC3.8-EGFP. Bright field images and corresponding fluorescent images of HBCs transfected with osteogenic reporter gene construct pOC3.8-EGFP (corresponding to figure 7). Cells were grown under proliferating and differentiating medium conditions over a period of 14 days. Images were taken at days $1,4,7,10$ and 14 . 